\title{
A thermodynamic model for sulfur content at sulfide saturation (SCSS) in hydrous silicate melts: with implications for arc magma genesis and $S$ recycling
} HUIJUAN LI AND LIFEI ZHANG

Peking University

Presenting Author: huijuan.li@pku.edu.cn

Modeling the effect of $\mathrm{H}_{2} \mathrm{O}$ on the "sulfur content at sulfide saturation" (SCSS) in silicate melt is essential for the estimation of SCSS in both arc magmas and slab melts. Here we present a SCSS model for hydrous silicate melt, in which SCSS has been modeled as a combination of $\mathrm{S}$ dissolving as $\mathrm{S}^{2-}$ and $\mathrm{HS}^{-} / \mathrm{H}_{2} \mathrm{~S}$, based on the sulfide capacity $\left(C_{\mathrm{S}}{ }^{2-}\right)$ and the hydro-sulfide capacity $\left(C_{\mathrm{HS}}\right)$, respectively. By adopting the thermodynamic framework of O'Neill and Mavrogenes [1], $\mathrm{S}$ dissolution as $\mathrm{HS}^{-} / \mathrm{H}_{2} \mathrm{~S}$ can be modeled in an analogous fashion to that for modeling $\mathrm{S}^{2-}$ in anhydrous melt. With the contribution of $\mathrm{S}$ dissolving as $\mathrm{S}^{2-}$ in basaltic and andesitic melts calculated based on the updated SCSS model for anhydrous basic melt from O'Neill [2], and $\mathrm{S}^{2-}$ considered negligible in rhyolitic and dacitic melts, we obtain an expression for $C_{\mathrm{HS}}$ based on a compilation of published experimental data on SCSS in hydrous silicate melts covering a $P T$ range of $0.15-3 \mathrm{GPa}$ and $785-1600^{\circ} \mathrm{C}$, and melt $\mathrm{H}_{2} \mathrm{O}$ contents of $\sim 1-13 \mathrm{wt} \%$.

Our model produces SCSS values for the primitive arc magmas compiled by Ruscitto et al. [3], that are in most cases higher than the measured $\mathrm{S}$ contents, implying sulfide undersaturated conditions during mantle wedge melting. The contribution of $\mathrm{H}_{2} \mathrm{~S}$ dissolution to the calculated SCSS values varies in a range of $82-1410 \mathrm{ppm}$, which increases with the increase of $\mathrm{H}_{2} \mathrm{O}$ content $\left(0.3-6.2 \mathrm{wt} \%\right.$ ). $\mathrm{H}_{2} \mathrm{~S}$ dissolution therefore contributes to the higher $\mathrm{S}$ content in arc basalt compared to MORB. Applying our current model to experimentally produced sediment melts spanning a $P T$ range of $690-1050{ }^{\circ} \mathrm{C}$ and $2.5-4.5$ $\mathrm{GPa}$, demonstrates that sediment melts, especially those of intermediate supercritical character with $>25 \mathrm{wt} \% \mathrm{H}_{2} \mathrm{O}$ and peralkaline in composition, can have high SCSS values as a result of $\mathrm{H}_{2} \mathrm{~S}$ dissolution, and act as the transfer medium for $\mathrm{S}$ recycling between the slab and mantle wedge under reduced conditions.

[1]O'Neill \& Mavrogenes (2002) J. Petrol. 43, 1049-1087. [2]O'Neill (2020) in: Earth and Space Science Open Archive.https://doi.org/10.1002/essoar.10503096.2 [3]Ruscitto et al. (2012) Geochemistry, Geophys. Geosystems 13, Q03025. 